NASA/TM-2004-212961
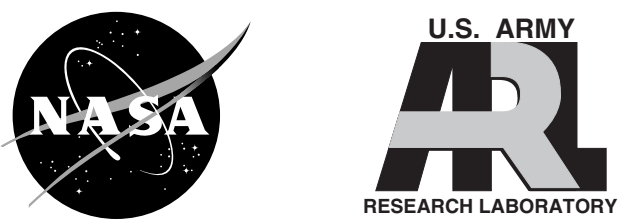

\title{
Development of Advanced Low Conductivity Thermal Barrier Coatings
}

Dongming Zhu

U.S. Army Research Laboratory, Glenn Research Center, Cleveland, Ohio

Robert A. Miller

Glenn Research Center, Cleveland, Ohio 
Since its founding, NASA has been dedicated to the advancement of aeronautics and space science. The NASA Scientific and Technical Information (STI) Program Office plays a key part in helping NASA maintain this important role.

The NASA STI Program Office is operated by Langley Research Center, the Lead Center for NASA's scientific and technical information. The NASA STI Program Office provides access to the NASA STI Database, the largest collection of aeronautical and space science STI in the world. The Program Office is also NASA's institutional mechanism for disseminating the results of its research and development activities. These results are published by NASA in the NASA STI Report Series, which includes the following report types:

- $\quad$ TECHNICAL PUBLICATION. Reports of completed research or a major significant phase of research that present the results of NASA programs and include extensive data or theoretical analysis. Includes compilations of significant scientific and technical data and information deemed to be of continuing reference value. NASA's counterpart of peerreviewed formal professional papers but has less stringent limitations on manuscript length and extent of graphic presentations.

- TECHNICAL MEMORANDUM. Scientific and technical findings that are preliminary or of specialized interest, e.g., quick release reports, working papers, and bibliographies that contain minimal annotation. Does not contain extensive analysis.

- CONTRACTOR REPORT. Scientific and technical findings by NASA-sponsored contractors and grantees.
- CONFERENCE PUBLICATION. Collected papers from scientific and technical conferences, symposia, seminars, or other meetings sponsored or cosponsored by NASA.

- SPECIAL PUBLICATION. Scientific, technical, or historical information from NASA programs, projects, and missions, often concerned with subjects having substantial public interest.

- TECHNICAL TRANSLATION. Englishlanguage translations of foreign scientific and technical material pertinent to NASA's mission.

Specialized services that complement the STI Program Office's diverse offerings include creating custom thesauri, building customized databases, organizing and publishing research results ... even providing videos.

For more information about the NASA STI Program Office, see the following:

- Access the NASA STI Program Home Page at http://www.sti.nasa.gov

- E-mail your question via the Internet to help@sti.nasa.gov

- Fax your question to the NASA Access Help Desk at 301-621-0134

- Telephone the NASA Access Help Desk at 301-621-0390

- Write to:

NASA Access Help Desk

NASA Center for AeroSpace Information 7121 Standard Drive

Hanover, MD 21076 
NASA/TM-2004-212961

ARL-TR-3259
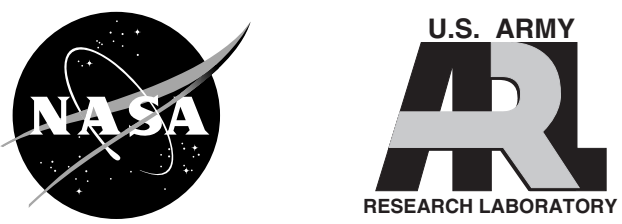

\section{Development of Advanced Low Conductivity Thermal Barrier Coatings}

Dongming Zhu

U.S. Army Research Laboratory, Glenn Research Center, Cleveland, Ohio

Robert A. Miller

Glenn Research Center, Cleveland, Ohio

National Aeronautics and

Space Administration

Glenn Research Center

July 2004 


\section{Acknowledgments}

This work was supported by the NASA Ultra-Efficient Engine Technology (UEET) Program. The authors gratefully acknowledge the help of their NASA colleagues, Narottam Bansal for hot-processed specimen processing,

Jeffrey I. Eldridge for emittance measurements, James A. Nesbitt and Charles A. Barrett for cyclic furnace testing of the coating materials. The authors are also grateful to George W. Leissler, QSS Group, Inc., at the NASA Glenn Research Center, for his assistance in the preparation of plasma-sprayed thermal barrier coatings, and to Robert W. Bruce, General Electric Aircraft Engines, and Kenneth S. Murphy, Howmet Research Corporation, for EB-PVD coating processing.

Available from

NASA Center for Aerospace Information 7121 Standard Drive

Hanover, MD 21076
National Technical Information Service 5285 Port Royal Road Springfield, VA 22100 


\title{
Development of Advanced Low Conductivity Thermal Barrier Coatings
}

\author{
Dongming Zhu \\ U.S. Army Research Laboratory \\ National Aeronautics and Space Administration \\ Glenn Research Center \\ Cleveland, Ohio 44135 \\ Robert A. Miller \\ National Aeronautics and Space Administration \\ Glenn Research Center \\ Cleveland, Ohio 44135
}

\begin{abstract}
Summary
Advanced multi-component, low conductivity oxide thermal barrier coatings have been developed using an approach that emphasizes real-time monitoring of thermal conductivity under conditions that are engine-like in terms of temperatures and heat fluxes. This is in contrast to the traditional approach where coatings are initially optimized in terms of furnace and burner rig durability with subsequent measurement in the as-processed or furnace-sintered condition. The present work establishes a laser highheat-flux test as the basis for evaluating advanced plasma-sprayed and electron beam-physical vapor deposited (EB-PVD) thermal barrier coatings under the NASA Ultra-Efficient Engine Technology (UEET) Program. The candidate coating materials for this program are novel thermal barrier coatings that are found to have significantly reduced thermal conductivities and improved thermal stability due to an oxide-defect-cluster design. Critical issues for designing advanced low conductivity coatings with improved coating durability are also discussed.
\end{abstract}

\section{Introduction}

Ceramic thermal barrier coatings (TBCs) are receiving increased attention for advanced gas turbine engine applications. The thermal barrier coatings are considered technologically important because of their ability to further increase engine operating temperatures and reduce cooling requirements, thus achieving higher engine efficiency, lower emission and increased performance goals. In order to fully take advantage of the TBC capability, an aggressive design approach-allowing greater temperature reductions through the coating systems and less cooling air to the components - is required whenever possible. Advanced thermal barrier coatings that have significantly lower thermal conductivity, better thermal stability and higher toughness than current coatings using advanced design approaches must be developed for future ultra efficient and low emission engine systems (ref. 1).

Higher surface temperatures and larger thermal gradients are expected in advanced thermal barrier coating systems as compared to conventional coating systems. As illustrated in figure 1, thermal barrier coatings with lower thermal conductivity can be used in thin coating configurations while still achieving sufficient temperature reductions at higher engine operating temperatures. The low conductivity coatings will have a significant advantage over the conventional ones particularly for rotating engine components (such as turbine blades), where a reduced weight is highly desirable. Considerable efforts have been made in order to develop advanced thermal barrier coatings with low conductivity and high thermal stability by modifying current $\mathrm{ZrO}_{2}-(7-8) \mathrm{wt}^{2} \mathrm{Y}_{2} \mathrm{O}_{3}$ coating microstructures and porosity (refs. 2 to 6 ), using 
alternative oxide ceramic compounds (refs. 7 to 13), and doping the $\mathrm{ZrO}_{2}$ - or $\mathrm{HfO}_{2}$-based solid solution alloy systems (refs. 1, 5, and 14 to 18). The multi-component doped, oxide alloy defect clustered thermal barrier coatings have been shown to offer the low conductivity and high stability required for future high temperature engine applications (refs. 15 to 18).

The development of low conductivity and high temperature stability thermal barrier coatings requires test techniques that can accurately and effectively evaluate coating thermal conductivity at high surface temperatures, typically in the range of 1300 to $1400{ }^{\circ} \mathrm{C}$. It is known that the coating thermal conductivity can increase significantly due to coating sintering and/or phase structure changes after a long-term thermal exposure. Therefore, evaluation of the initial and post-exposure thermal conductivities, and the rate-of-conductivity-increase is crucial in characterizing the coating's performance. In this study, a laser high-heat-flux test technique has been developed for evaluating advanced plasma-sprayed and electron beam-physical vapor deposited (EB-PVD) thermal barrier coatings under the NASA Ultra Efficient Engine Technology (UEET) program. The test approach emphasizes real-time monitoring of thermal conductivity and, therefore, the conductivity increases at high temperature under simulated engine thermal gradients to determine the optimum coating compositions. Novel candidate thermal barrier coating materials are developed using an oxide defect clustering concept that incorporates paired rareearth oxide cluster dopants into zirconia-yttria or hafnia-yttria systems (refs. 16 and 18), thereby achieving low thermal conductivity and sintering resistant coating systems. The coating durability issues and the dopant effect on coating furnace cyclic behavior are also discussed.

\section{Experimental Materials and Methods}

\section{Advanced Defect-Clustering Oxide Thermal Barrier Coatings}

Advanced low conductivity and high stability thermal barrier coatings were developed using a multicomponent oxide defect-clustering approach (refs. 1, 15, and 16). The advanced oxide coatings were designed by incorporating multi-component, paired-cluster rare-earth oxide dopants into conventional zirconia- and hafnia-yttria oxide systems. The dopant oxides were selected by considering their interatomic and chemical potentials, lattice elastic strain energy (ionic size effect), polarization as well as electro-neutrality within the oxides. The added dopant oxides were intended to effectively promote the creation of thermodynamically stable, highly defective lattice structures with essentially immobile defect clusters and/or nanoscale ordered phases, thus reducing oxide coating thermal conductivity and improving coating sintering resistance (ref. 15).

In the present study, selected oxide cluster thermal barrier coating systems including $\mathrm{ZrO}_{2}-\mathrm{Y}_{2} \mathrm{O}_{3}$ $\mathrm{Nd}_{2} \mathrm{O}_{3}\left(\mathrm{Gd}_{2} \mathrm{O}_{3}, \mathrm{Sm}_{2} \mathrm{O}_{3}\right)-\mathrm{Yb}_{2} \mathrm{O}_{3}\left(\mathrm{Sc}_{2} \mathrm{O}_{3}\right)$ were synthesized, and their conductivity and sintering behavior was investigated. Emphasis was placed on the effect of total dopant concentrations on the coating thermal conductivity, sintering resistance, and durability. The advanced thermal barrier coating systems, typically consisting of a 180 to $250 \mu \mathrm{m}$ ceramic top coat and a 75 to $120 \mu \mathrm{m}$ NiCrAlY or PtAl intermediate bond coat, were either plasma-sprayed or electron-beam physical vapor deposited on to the $25.4 \mathrm{~mm}$ diameter and $3.2 \mathrm{~mm}$ thick Rene N5 disk substrates. The plasma-sprayed coatings were processed using prealloyed powders. The ceramic powders with designed compositions were first spray-dried, then plasmareacted and spheroidized, and finally plasma-sprayed into the coating form. The advanced EB-PVD coatings were deposited using pre-fabricated evaporation ingots that were made of the carefully designed compositions. The EB-PVD coatings were processed into test coating specimens by two different vendors (General Electric Aircraft Engines, Cincinnati, Ohio, and Howmet Coatings Corporation, Whitehall, Michigan). 


\section{Laser Test Approach for Evaluating Advanced Thermal Barrier Coatings}

A $3.0 \mathrm{~kW} \mathrm{CO} 2$ laser (wavelength $10.6 \mu \mathrm{m}$ ) high-heat-flux thermal conductivity rig was established for evaluating advanced thermal barrier coatings. The general approaches used for coating conductivity measurement under the high temperature and high thermal gradient conditions have been described in detail elsewhere (refs. 19 to 22). During the testing, a large thermal gradient in the ceramic coating can be established by the laser surface heating and backside air-cooling. A given constant laser-delivered heat flux was applied to the coating surface throughout a $20 \mathrm{hr}$ steady-state test period. Thermal conductivity of each candidate ceramic coating was determined in real-time during the laser test, based on the applied laser heat flux and the measured temperature gradient across the coating. The surface temperature for all test specimens was at $1316^{\circ} \mathrm{C}$ at the beginning of the tests. The coating/metal interface temperature was approximately in the range of 950 to $1100{ }^{\circ} \mathrm{C}$, depending on the coating thermal conductivity and applied laser heat flux. Since the coating conductivity increases with time due to ceramic sintering, the coating surface temperature will continuously drop under the fixed laser heat-flux condition. The measured initial coating conductivity $\left(k_{0}\right)$, the conductivity at $20 \mathrm{hrs}\left(k_{20}\right)$, and the conductivity rate of increase were used for evaluating the candidate coating performance. It should be mentioned that for some of the EB-PVD oxide coating systems, the coating conductivity after $5 \mathrm{hrs}$ testing $\left(k_{5}\right)$ was used for characterizing the coating behavior. This is a viable approach for effectively reducing the testing time, because the EB-PVD coatings usually reached a steady-state conductivity increase stage after $5 \mathrm{hrs}$ of testing, with a relatively low subsequent rate of conductivity increase.

\section{Experimental Results}

\section{Thermal Conductivity of Advanced Thermal Barrier Coatings}

Figure 2 illustrates the high temperature thermal conductivity of plasma-sprayed oxide cluster thermal barrier coatings as a function of test time. The advanced oxide coatings investigated in this study consisted primarily of $\mathrm{ZrO}_{2}-\mathrm{Y}_{2} \mathrm{O}_{3}$, but were also co-doped with additional paired rare earth oxides $\mathrm{Nd}_{2} \mathrm{O}_{3}$ $\mathrm{Yb}_{2} \mathrm{O}_{3}$ or $\mathrm{Gd}_{2} \mathrm{O}_{3}-\mathrm{Yb}_{2} \mathrm{O}_{3}$ (i.e., YSZ-Nd-Yb and $\mathrm{YSZ}-\mathrm{Gd}-\mathrm{Yb}$ oxide systems). As a comparison, the thermal conductivity of a baseline coating, $\mathrm{ZrO}_{2}-4.55 \mathrm{~mol} \% \mathrm{Y}_{2} \mathrm{O}_{3}$ (i.e., $\mathrm{ZrO}_{2}-8 \mathrm{wt} \% \mathrm{Y}_{2} \mathrm{O}_{3}$, or $8 \mathrm{YSZ}$ ), is also plotted in figure 2 . It can be seen that the coating conductivity generally increased with time. The advanced oxide cluster coating systems exhibited much lower thermal conductivity and conductivity increases than the conventional baseline coating. As shown in figure 2(a), approximately one third of the 20-hr baseline coating conductivity value was achieved for some of best coating systems after the $20 \mathrm{hr}$ laser high temperature tests. Figure 2(b) shows that the plasma-sprayed $\mathrm{ZrO}_{2}-13.5 \%(\mathrm{Y}, \mathrm{Nd}, \mathrm{Yb})_{2} \mathrm{O}_{3}$ coating achieved almost one order-of-magnitude lower conductivity rate of increase as compared to the $\mathrm{ZrO}_{2}$ $4.55 \mathrm{~mol} \% \mathrm{Y}_{2} \mathrm{O}_{3}$ baseline coating.

Figure 3 shows thermal conductivity and the rate of conductivity increase, of various plasma-sprayed oxide cluster thermal barrier coatings as a function of total dopant concentration. Figure 3(a) illustrates the initial and 20-hr conductivity values of the coatings. It can be seen that the baseline 4.55YSZ coating had an initial conductivity of about $1.0 \mathrm{~W} / \mathrm{m}-\mathrm{K}$. The conductivity of the baseline coating increased to about $1.4 \mathrm{~W} / \mathrm{m}-\mathrm{K}$ after 20 hours of high-heat-flux testing. In contrast, the oxide cluster coatings, including YSZ-Nd-Yb, YSZ-Gd-Yb and YSZ-Sm-Yb systems, exhibited lower initial and 20-hr thermal conductivities than the baseline coating. Thermal conductivity of the oxide cluster coatings generally decreased with increasing total dopant concentration. However, a very low conductivity region was observed in the concentration range that contains 6 to $13 \mathrm{~mol} \%$ of the total dopants. Similar behavior was observed for the rate of conductivity increase data, shown in figure 3(b). A minimum region for the rate of increase was also observed in the dopant concentration range of 6 to $13 \mathrm{~mol} \%$, corresponding well with the low conductivity valley region for the conductivity of the coating systems. 
In order to investigate the effect of the cluster dopant concentration ratio on conductivity, plasmasprayed $\mathrm{ZrO}_{2}-\mathrm{Y}_{2} \mathrm{O}_{3}-\mathrm{Nd}_{2} \mathrm{O}_{3}-\mathrm{Yb}_{2} \mathrm{O}_{3}$ oxide coatings with decoupled cluster dopant concentrations were designed and prepared near the optimum low conductivity region. This set of oxide coatings had compositions ranging from YSZ only, YSZ plus a single $\mathrm{Nd}_{2} \mathrm{O}_{3}$ or $\mathrm{Yb}_{2} \mathrm{O}_{3}$ dopant, YSZ plus both the $\mathrm{Nd}_{2} \mathrm{O}_{3}$ or $\mathrm{Yb}_{2} \mathrm{O}_{3}$ but in varying the relative concentrations (with either equal or non-equal cluster dopant concentrations). Figure 4 shows the thermal conductivity results of the YSZ-Nd-Yb oxide thermal barrier coatings as a function of total dopant concentration and cluster dopant concentration ratio $\left(\right.$ ratio of $\mathrm{Yb}_{2} \mathrm{O}_{3}$ to $\mathrm{Nd}_{2} \mathrm{O}_{3}$ in mol\%). It can be seen that thermal barrier coatings of $\mathrm{ZrO}_{2}-\mathrm{Y}_{2} \mathrm{O}_{3}$, and $\mathrm{ZrO}_{2}-\mathrm{Y}_{2} \mathrm{O}_{3}$ with a single cluster dopant, $\mathrm{Nd}$ or $\mathrm{Yb}$, showed typically higher thermal conductivities than the coatings of $\mathrm{ZrO}_{2}$ $\mathrm{Y}_{2} \mathrm{O}_{3}$ with paired dopant additions $\left(\mathrm{Nd}_{2} \mathrm{O}_{3}+\mathrm{Yb}_{2} \mathrm{O}_{3}\right)$. The oxide cluster coatings with equal amount of cluster dopants added $\left(\mathrm{Yb}_{2} \mathrm{O}_{3} / \mathrm{Nd}_{2} \mathrm{O}_{3}=1\right)$ often showed the lowest conductivity at a given total dopant concentrations. The paired dopants (with equal cluster dopant concentrations) especially showed significant beneficial effects in reducing the coating conductivity at about $10 \mathrm{~mol} \%$ dopant concentrations.

Thermal conductivity of electron-beam physical vapor-deposited (EB-PVD) oxide cluster thermal barrier coatings was also investigated using the laser heat flux technique. Figure 5 shows typical conductivity changes as a function of time for EB-PVD processed $\mathrm{ZrO}_{2}-(4 \sim 6 \mathrm{~mol} \%) \mathrm{Y}_{2} \mathrm{O}_{3}-\mathrm{Nd}-\mathrm{Yb}$ oxide cluster coatings. It can be seen that the oxide cluster coatings exhibited lower thermal conductivities and the rates of conductivity increase compared to the baseline $\mathrm{ZrO}_{2}-4.55 \mathrm{~mol} \% \mathrm{Y}_{2} \mathrm{O}_{3}$ coating. The conductivity for the oxide cluster coatings can be as low as $0.85 \mathrm{~W} / \mathrm{m}-\mathrm{K}$ after the 20 -hr high temperature testing, as compared to the conductivity of $1.85-1.90 \mathrm{~W} / \mathrm{m}-\mathrm{K}$ for the baseline coating. The rate of conductivity increase was also reduced to $0.8 \times 10^{-6} \sim 1.0 \times 10^{-6} \mathrm{~W} / \mathrm{m}-\mathrm{K}-\mathrm{s}$ from the baseline coating value of $1.3 \times 10^{-6} \mathrm{~W} / \mathrm{m}-\mathrm{K}-\mathrm{s}$ by the addition of the cluster dopants.

Figure 6 illustrates thermal conductivity of various oxide cluster thermal barrier coatings as a function of total dopant concentration after 5 or $20 \mathrm{hr}$ laser high heat flux tests at $1316^{\circ} \mathrm{C}$. The conductivity data were plotted for selected NASA composition oxide cluster coatings that were prepared at General Electric Aircraft Engines Company and Howmet Coatings Corporation. Note that for some coating systems, the 5 -hr conductivity data $k_{5}$ (instead of 20-hr conductivity data $k_{20}$ ) were used. This is still an acceptable approach based on the considerations that there is only small differences between $k_{5}$ and $k_{20}$ for the oxide cluster EB-PVD coatings, simply because the coatings have reached a steady-state conductivity increase stage and also have relatively low rates of conductivity increase. It can be seen that the EB-PVD coating systems generally showed lower thermal conductivity than the YSZ coatings at any given total dopant concentration. In addition, similar to the plasma-sprayed coatings, the EB-PVD coating systems also exhibited a low conductivity region which is centered around $10 \mathrm{~mol} \%$ total dopant concentration.

\section{Furnace Cyclic Behavior of the Advanced Thermal Barrier Coatings}

Furnace cyclic oxidation tests have been carried out to evaluate durability of the advanced oxide coating systems. The coating specimens were thermal cyclic tested at $1160^{\circ} \mathrm{C}$ using a tubular or a box furnace with 45 min hot time cycles (ref. 23). Figure 7 summarizes the test results for various coating compositions which were processed from different batches. It can be seen that, regardless of the relatively large scatter, the coating cyclic life generally decreased with increasing total dopant concentration. The oxide cluster coatings followed a similar trend as compared to the yttria-zirconia (YSZ only) coatings in the furnace cyclic behavior. However, the present results suggest some beneficial effect in improving coating cyclic durability by the addition of cluster oxide dopants. The multi-component cluster oxide coatings typically showed better cyclic durability than only yttria-doped zirconia coatings at given dopant concentrations. In fact, within the optimum low conductivity region of 6 to $13 \mathrm{~mol} \%$ dopant concentration, significant coating life improvements (in some cases, coating lives comparable to those of zirconia-4.55 mol\%yttria) have been observed for the initial processed (no processing optimization) oxide cluster coatings as compared to the yttria stabilized zicornia coatings. Moderate coating life increases 
were also observed by coating composition, microstructure and bond coat modifications (ref. 23). Further life improvements will be expected by utilizing advanced coatings architecture design, dopant type and composition optimization, and improved processing techniques.

\section{Discussion}

The intrinsic thermal conductivity of a ceramic coating is closely related to its lattice structure and lattice defects. The interactions between lattice phonon waves, and scattering of the lattice phonon and radiative photon waves by various length scale defects will greatly affect the thermal conductivity behavior (ref. 24). As mentioned earlier, the multi-dopant oxides were incorporated into the $\mathrm{ZrO}_{2}-\mathrm{Y}_{2} \mathrm{O}_{3}$ system by considering their interatomic and chemical potentials, lattice elastic strain energy (ionic size effect), polarization and electro-neutrality within the oxides (ref. 15). The defect cluster design approach, using the high stability, paired dopant oxides of distinctively different ionic sizes, will effectively produce lattice distortion in the oxide solid solutions and facilitate local ionic segregation and thus defect clustering. Oxide defect clusters with appropriate sizes can effectively attenuate and scatter lattice phonon waves as well as radiative photon waves at a wide spectrum of frequencies. Therefore, by promoting the creation of thermodynamically stable, highly defective lattice structures with controlled defect cluster sizes, one can expect a reduced oxide intrinsic lattice and radiation thermal conductivity for theses coatings.

The measured thermal conductivity for plasma-sprayed and EB-PVD thermal barrier coatings include both the contributions from the intrinsic coating conductivity and from the microstructural (such as coating porosity) effect. The coating thermal conductivity can be greatly reduced by the presence of microcracks and microporosity within the ceramic coatings. However, the conductivity reduction achieved by micro-porosity may not persist at high temperatures. The laser thermal conductivity test data for both the plasma-sprayed and EB-PVD thermal barrier coatings showed a significant coating conductivity increase with time. The increase in measured coating thermal conductivity has been attributed to ceramic sintering and densification (refs. 20 and 21). The advanced cluster oxide thermal barrier coatings showed reduced conductivity increase rates and thus improved sintering resistance due to the addition of the dopant oxides.

The added cluster dopant oxides can facilitate the formation of defective oxide lattice structures with essentially immobile defect clusters and/or nanoscale ordered phases, which improves the coating sintering resistance. The defect clustering phenomena have been observed in the multi-component rareearth oxide doped thermal barrier coatings using high-resolution transmission electron microcopy (ref. 17). As exemplified for the $\mathrm{ZrO}_{2}$ - or $\mathrm{HfO}_{2}$-based oxide systems, the following reactions, describing the defect clustering and dissociation, can be written using Kröger-Vink notation (ref. 25):

$$
\begin{gathered}
{\left[\left(M f_{M}^{\prime}\left(M f^{3+}\right)\right) V_{\ddot{o}}\right] \Leftrightarrow M f_{M}^{\prime}\left(M f^{3+}\right)+V_{\ddot{o}} \text { (for a two-member defect complex case) }} \\
{\left[\left(M f_{M}^{\prime}\left(M f^{3+}\right)\right) V_{\ddot{o}}\left(M f_{M}^{\prime}\left(M f^{3+}\right)\right)\right]^{X} \Leftrightarrow 2 M f_{M}^{\prime}\left(M f^{3+}\right)+V_{\ddot{o}} \text { (for a three-member defect complex case) }} \\
{[\text { defect clusters, sub-microdomains }]^{\mathrm{n}} \Leftrightarrow \text { single point defects (for a general defect cluster case) }}
\end{gathered}
$$

where $\left(M f_{M}^{\prime}\left(M f^{3+}\right)\right)$ is a valence defect for a dopant cation (valence +3 ) at the $\mathrm{Zr}($ valence +4$)$ site, and $V_{\ddot{o}}$ is the anion oxygen vacancy. Because the defect clusters are in dynamic equilibrium with the single point defects at high temperatures, the sophisticated oxide cluster design may suppress the cluster 
dissociation reactions at extremely high temperatures. By reducing the mobile defect concentrations through the defect clustering, the atomic (both cationic and anionic) mobility and mass transport within the oxides can be greatly reduced. This can explain why the oxide cluster thermal barrier coatings exhibited a lower conductivity rate of increase and thus the sintering resistance than the baseline yttria partially-stabilized zirconia coatings.

The thermal conductivity and the conductivity rate increase showed a clear minimum for the oxide cluster thermal barrier coatings at about $10 \mathrm{~mol} \%$ total dopant concentration. This composition approximately corresponds to the phase boundary between the tetragonal phase zirconia (for the partiallystabilized zirconia, $t^{\prime}$ phase) and cubic phase zirconia at the testing temperatures. It is possible that the oxide defect clustering occurs most extensive near this phase boundary, thus showing the maximum conductivity reductions and the minimum conductivity rates of increase. The sophisticated compositional design approach will expect to significantly reduce thermal conductivity, improve sintering-creep resistance and other mechanical properties (such as fracture toughness) at high temperatures, for both the $\mathrm{ZrO}_{2}$-based cubic and tetragonal phase coating systems.

\section{Conclusions}

Advanced multi-component, low conductivity oxide thermal barrier coatings have been developed based on an oxide-defect-clustering design approach and using a laser high-heat-flux thermal conductivity technique. The laser test approach emphasizes real-time monitoring of the coating conductivity at high temperatures in order to assess the overall coating thermal conductivity performance under engine-like heat flux and thermal gradient conditions.

The durability of the advanced low conductivity coatings was evaluated using cyclic furnace tests. Although the advanced oxide cluster coatings followed a similar trend as the pseudo-binary $\mathrm{ZrO}_{2}-\mathrm{Y}_{2} \mathrm{O}_{3}$ coatings in the furnace cyclic behavior where the coating cyclic life generally decreases with increasing the total dopant concentration, the oxide cluster coatings showed promise to have significantly better cyclic durability (comparable to that of zirconia-4.55mol\%yttria) than the binary $\mathrm{ZrO}_{2}-\mathrm{Y}_{2} \mathrm{O}_{3}$ coatings with equivalent dopant concentrations. Further life improvements will be expected by utilizing advanced coating architecture design, dopant type and composition optimization, and improved processing techniques. The advanced low conductivity thermal barrier coatings will be developed with long-term cyclic durability and stability at very high temperatures which are far beyond the current $\mathrm{ZrO}_{2}-\mathrm{Y}_{2} \mathrm{O}_{3}$ coating capabilities.

\section{References}

1. D. Zhu and R.A. Miller, "Defect Cluster Design Considerations in Advanced Thermal Barrier Coatings," NASA UEET Presentation, NASA Glenn Research Center, Cleveland, Ohio, November 1999.

2. D.D. Hass, A.J. Slifka, and H.N.G. Wadley, "Low Thermal Conductivity Vapor Deposited Zirconia Microstructures," Acta Materialia, 49 (2001), pp. 973-983.

3. S. Gu, T.J. Lu, D.D. Haas, and H.N.G. Wadley, "Thermal Conductivity of Zirconia Coatings with Zig-Zag Pore Microstructures," Acta Materialia, 49 (2001), pp. 2539-2547.

4. Tian J. Lu, Carlos G. Levi, Haydn N.G. Wadley, Anthony G. Evans, "Distributed Porosity as a Control Parameter for Oxide Thermal Barriers by Physical Vapor Deposition," Journal of the American Ceramic Society, 84 (2001), pp. 2937-2946.

5. J.R. Nicholls, K.J. Lawson, A. Johnstone, D.S. Rickerby, "Method to reduce the thermal conductivity of EB-PVD TBCs," Surface and Coatings Technology, pp. 151-152 (2002), 383-391. 
6. A. Kulkarni, Z. Wang, T. Nakamura, S. Sampath, A. Goland, H. Herman, J. Allen, J. Ilavsky, G. Long, J. Frahm, R. W. Steinbrech, "Comprehensive Microstructural Characterization and Predictive Property Modeling of Plasma-Sprayed Zirconia Coatings," Acta Materialia, 51 (2003), pp. 2457-2475.

7. M. J. Malony, "Thermal Barrier Coating Systems and Materials," US Pat. No. 6,284,323, September 2001.

8. R. Subramanian, "Thermal Barrier Coating Having High Phase stability", US Pat. No. 6,387,539, May 2002.

9. Jie Wu, Xuezheng Wei, Nitin P. Padture, Paul G. Klemens, Maurice Gell, Eugenio García, Pilar Miranzo, and Maria I. Osendi, "Low-Thermal-Conductivity Rare-Earth Zirconates for Potential Thermal-Barrier-Coating Applications," Journal of the American Ceramic Society, 85 (2002), pp. 3031-3035.

10. Henry Lehmann, Dieter Pitzer, Gerhard Pracht, Robert Vassen, and Detlef Stöver, "Thermal Conductivity and Thermal expansion Coefficients of the Lanthanum Rare-Earth-Element Zirconate System," Journal of the American Ceramic Society, 86 (2003), pp. 1338-1344.

11. Ulrich Bast, and Eckart Schumann, "Development of Novel Oxide Materials for TBCs", Ceramic Eng. Sci. Proc., 23 (2002), pp. 525-532.

12. R. Gadow, and M. Lischka, "Lanthanum Hexaaluminate-Novel Thermal Barrier Coatings for Gas Turbine Applications-Materials and Process Development," Surface and Coatings Technology, 151-152 (2002), pp. 392-399.

13. Dongming Zhu, Narottam P. Bansal, and Robert A. Miller, "Thermal conductivity and Stability of Hafnia- and Zirconate-Based Materials for $1650^{\circ} \mathrm{C}$ Thermal/Environmental Barrier Coating Applications," Ceramic Transactions, 153 (2003). Also NASA/TM-2003-212544.

14. Dongming Zhu, and Robert A. Miller, "Sintering and Creep Behavior of Plasma-Sprayed Zirconia and HfO2-Based Thermal Barrier Coatings," Surface and Coatings Technology, 108-109 (1998), pp. 114-120.

15. Dongming Zhu, and Robert A. Miller, "Low Conductivity and Sintering Resistant Thermal Barrier Coatings," US Provisional Patent Application Serial No. 60/263,257, USA; US Patent Application Serial No. 09/904,084, USA, January 2001.

16. Dongming Zhu, and Robert A. Miller, "Thermal Conductivity and Sintering Behavior of Advanced Thermal Barrier Coatings," Ceramic Eng. Sci. Proc., Vol. 23 (2002), 457-468.

17. Dongming Zhu, Yuan L. Chen and Robert A. Miller, "Defect Clustering and Nano-phase Structure Characterization of Multicomponent Rare-Earth Oxide Doped Zirconia-Yttria Thermal Barrier Coatings," Ceramic Eng. Sci. Proc., Vol. 24 (2003). Also NASA/TM-2003-212480.

18. Dongming Zhu, and Robert A. Miller, "Hafnia-Based Materials Development for Advanced Thermal/Environmental Barrier Coating Applications," in Research and Technology 2003, NASA Glenn Research Center, NASA TM, in press.

19. Dongming Zhu, and Robert A. Miller, "Thermal Conductivity Change Kinetics of Ceramic Thermal Barrier Coatings Determined by the Steady-State Laser Heat Flux Technique," in Research and Technology 1999, NASA Glenn Research Center, NASA/TM-2000-209639, 29-31.

20. Dongming Zhu, and Robert A. Miller, "Thermal Conductivity and Elastic Modulus Evolution of Thermal Barrier Coatings Under High Heat Flux Conditions," Journal of Thermal Spray Technology, vol. 9, pp. 175-180, 2000.

21. Dongming Zhu, Robert A. Miller, Ben A. Nagaraj, and Robert W. Bruce, "Thermal Conductivity of EB-PVD Thermal Barrier Coatings Evaluated by a Steady-State Laser Heat Flux Technique," Surface and Coatings Technology, vol. 138, pp. 1-8, 2001. 
22. Dongming Zhu, Narottam P. Bansal, Kang N. Lee and Robert A. Miller, "Thermal Conductivity of Ceramic Coating Materials Determined by a Laser Heat Flux Technique," High Temperature Ceramic Matrix Composites IV, Proc. the 4th High Temperature Ceramic Matrix Composites Conference (HT-CMC 4), Munich, Germany, Oct. 1-3 (2001), Edited by W. Krenkel, R. Naslain, and H. Schneider, Wiley-VCH, Verlag GmBH, Germany, 2001, 262-267. Also NASA/TM-2001211122, NASA Glenn Research Center, Cleveland.

23. Dongming Zhu, James A. Nesbitt, Terry R. McCue, Charles A. Barrett, and Robert A. Miller, "Furnace Cyclic Behavior of Plasma-Sprayed Zirconia-Yttria and Multi-Component Rare Earth Doped Thermal Barrier Coatings," Ceram. Eng. Sci. Proc., 23 (2002), 533-546.

24. P.G. Klemens and M. Gell, "Thermal Conductivity of Thermal Barrier Coatings," Materials Science and Engineering, vol. A245, pp. 143-149, 1998.

25. F.A. Kröger, The Chemistry of Imperfect Crystals, Amsterdam: North-Holland, 1964.

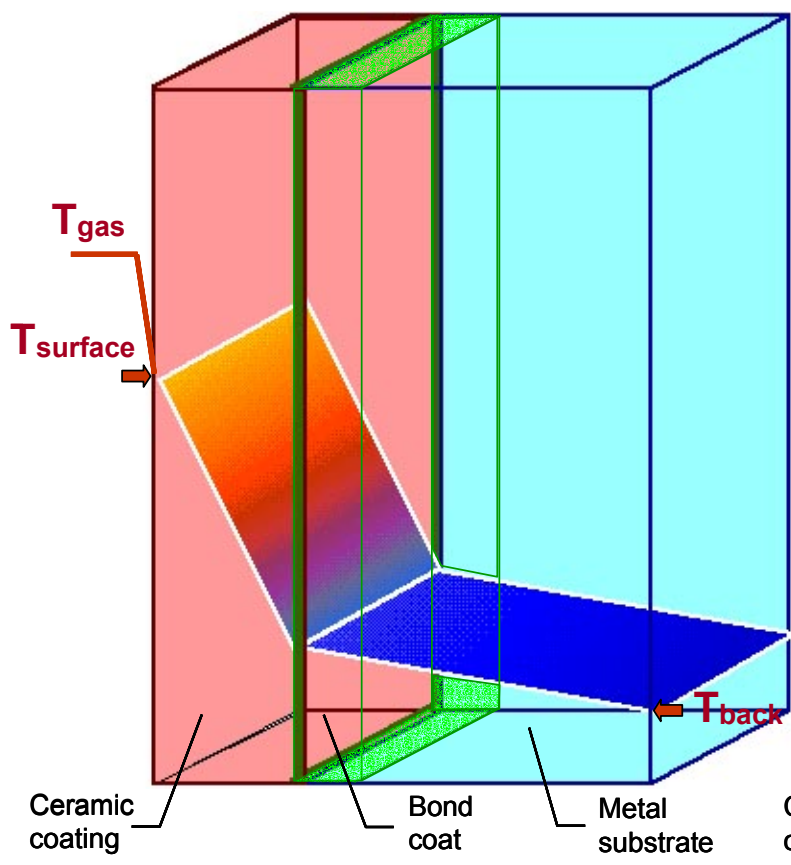

(a)

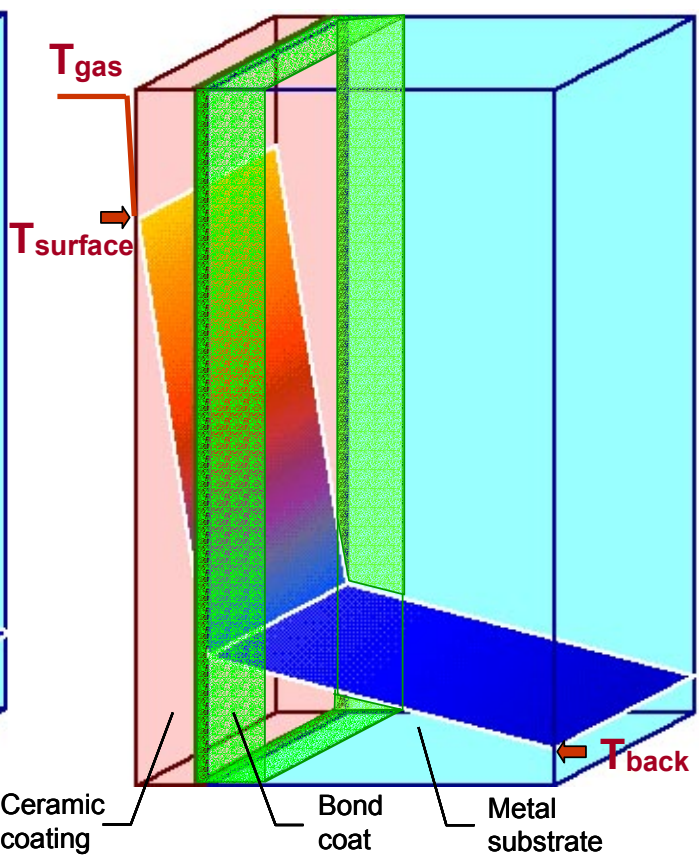

(b)

Figure 1. Advanced thermal barrier coatings with lower thermal conductivity and better temperature stability will allow the use of a thinner coating system to achieve a larger temperature reduction at higher engine operating temperatures. The substrate temperature can be maintained at a lower level while the cooling can be significantly reduced. A thin coating system is highly desirable for engine rotating components such as airfoils where a reduced weight is critical. (a) Current TBCs. (b) Advanced TBCs. 


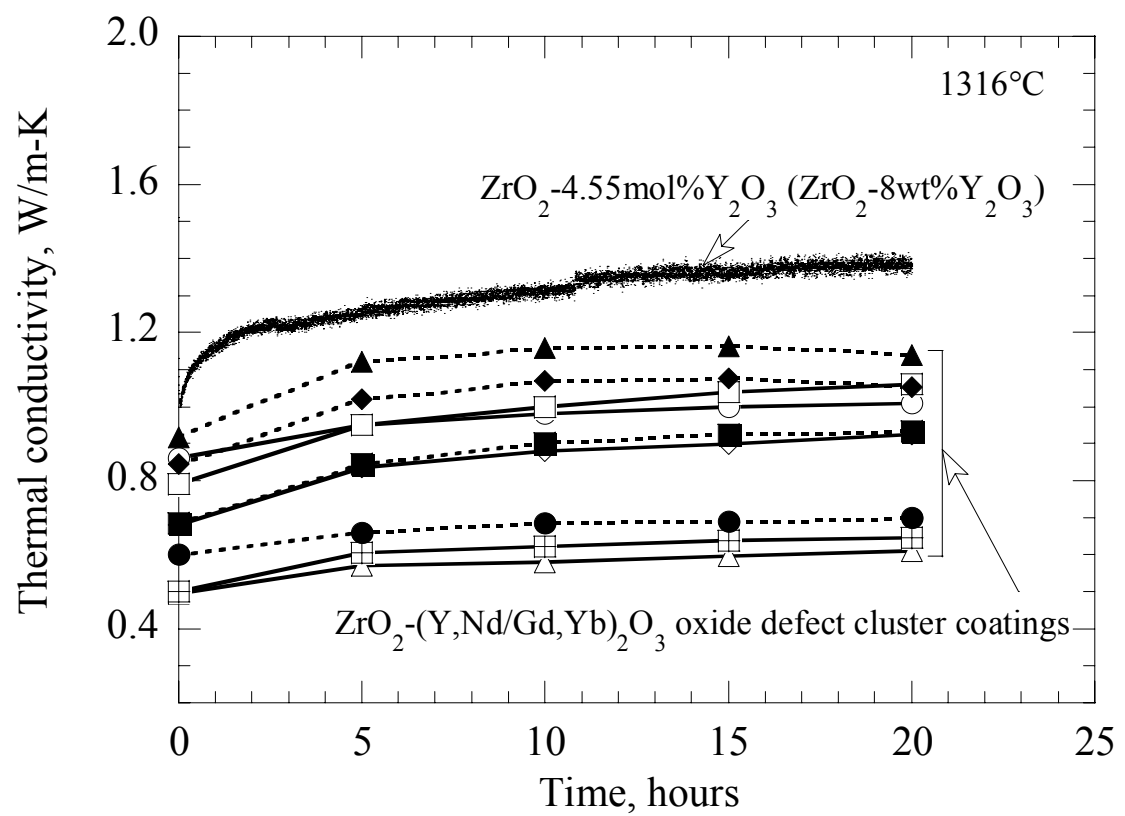

(a)

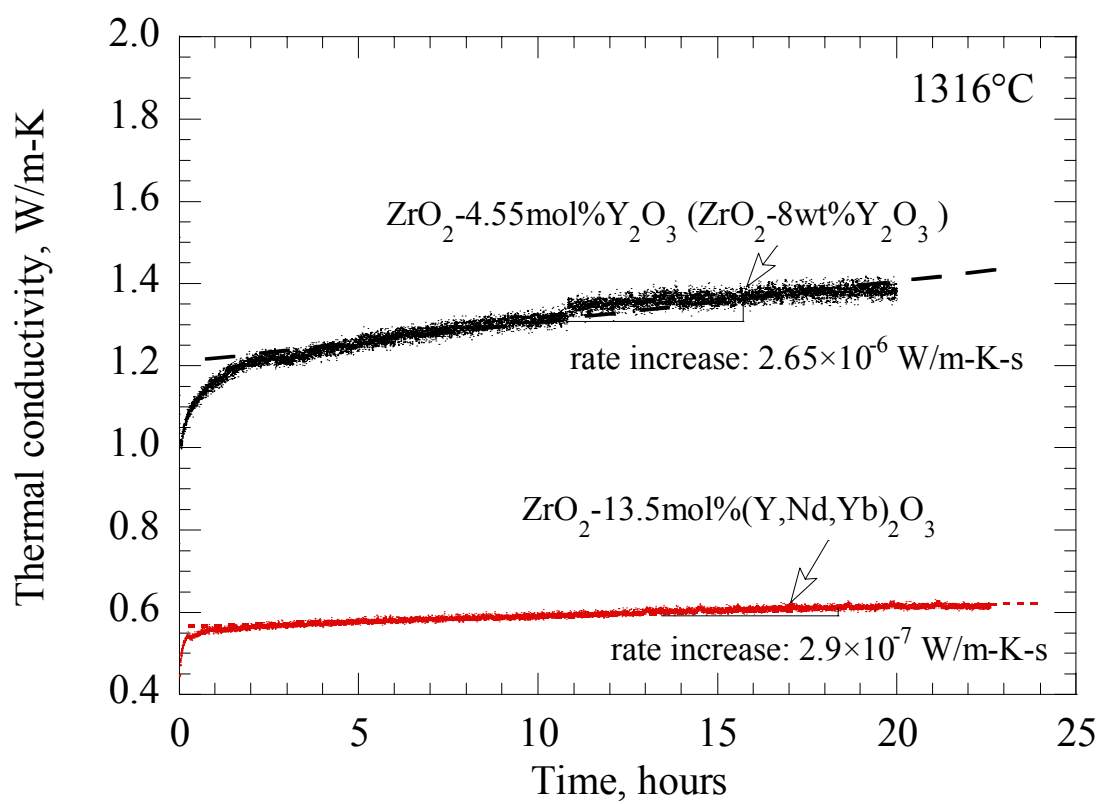

(b)

Figure 2. Thermal conductivity of plasma-sprayed multi-component $\mathrm{ZrO}_{2}-(\mathrm{Y}, \mathrm{Nd} / \mathrm{Gd}, \mathrm{Yb})_{2} \mathrm{O}_{3}$ and $\mathrm{ZrO}_{2}-$ $4.55 \mathrm{~mol} \% \mathrm{Y}_{2} \mathrm{O}_{3}$ coatings as a function of time, determined using a steady-state laser heat-flux technique at the surface temperature of $1316^{\circ} \mathrm{C}$. (a) Thermal conductivity of various composition $\mathrm{ZrO}_{2}-(\mathrm{Y}, \mathrm{Nd}, \mathrm{Yb})_{2} \mathrm{O}_{3}$ and $\mathrm{ZrO}_{2}-(\mathrm{Y}, \mathrm{Gd}, \mathrm{Yb})_{2} \mathrm{O}_{3}$ oxide coating systems. (b) Thermal conductivity rate of increase for the $\mathrm{ZrO}_{2}-$ $13.5 \mathrm{~mol} \%(\mathrm{Y}, \mathrm{Nd}, \mathrm{Yb})_{2} \mathrm{O}_{3}$ and $\mathrm{ZrO}_{2}-4.55 \mathrm{~mol} \% \mathrm{Y}_{2} \mathrm{O}_{3}$ coatings. 


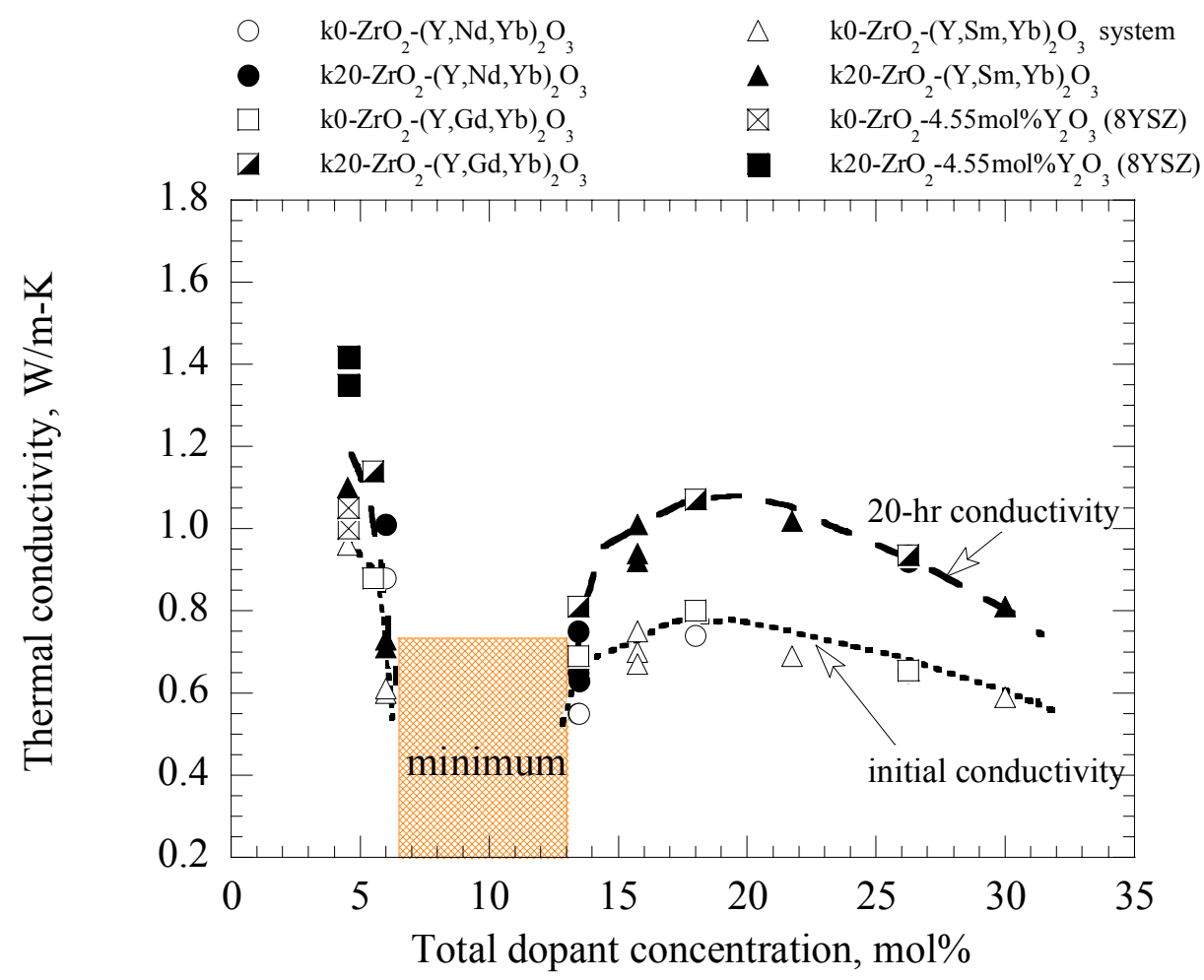

(a)

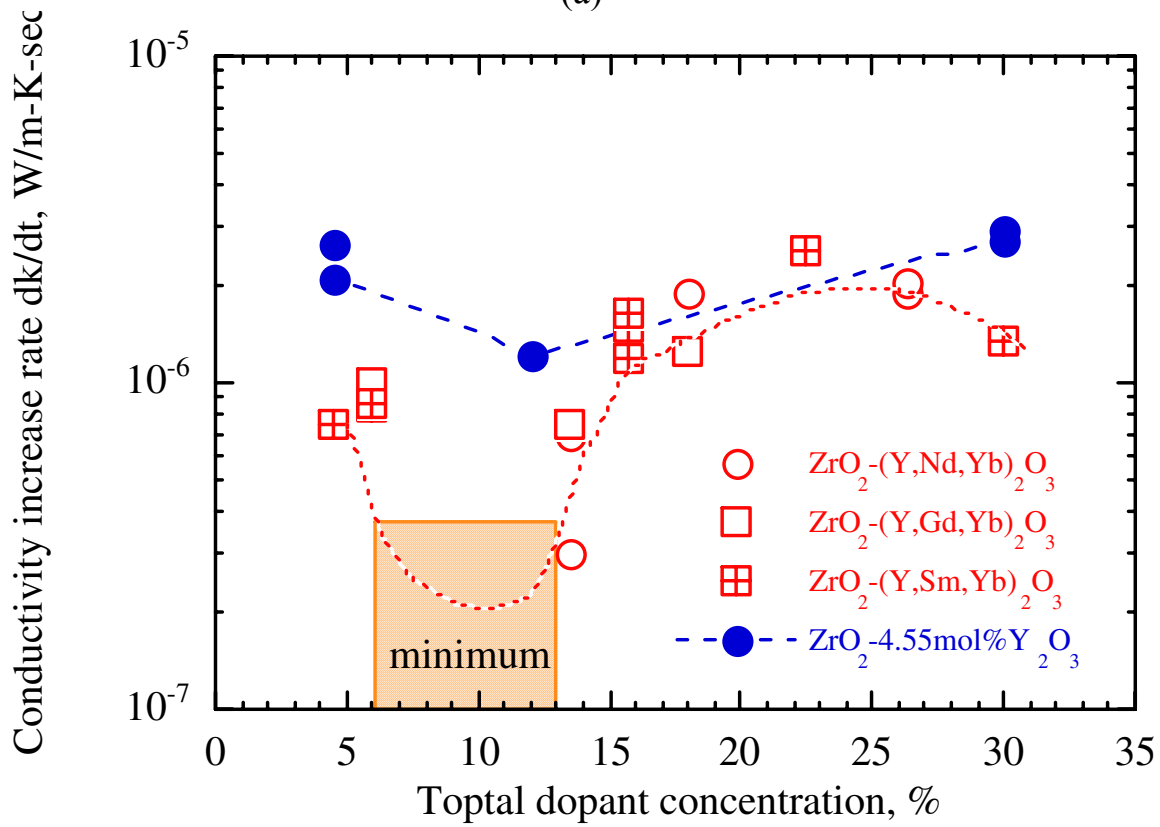

(b)

Figure 3. Thermal conductivity, and the conductivity rate of increase, of $\mathrm{ZrO}_{2}-(\mathrm{Y}, \mathrm{Nd}, \mathrm{Yb})_{2} \mathrm{O}_{3}, \mathrm{ZrO}_{2}$ $(\mathrm{Y}, \mathrm{Gd}, \mathrm{Yb})_{2} \mathrm{O}_{3}$, and $\mathrm{ZrO}_{2}-(\mathrm{Y}, \mathrm{Sm}, \mathrm{Yb})_{2} \mathrm{O}_{3}$ plasma-sprayed oxide defect cluster coatings as a function of total dopant concentration, determined using a steady-state laser heat-flux technique at the surface temperature of $1316^{\circ} \mathrm{C}$. A low conductivity and low-rate-increase regime is observed in the range of 6 to $13 \mathrm{~mol} \%$ total dopant concentration. (a) Initial and $20 \mathrm{hr}$ thermal conductivity. (b) Corresponding conductivity rate of increase. 


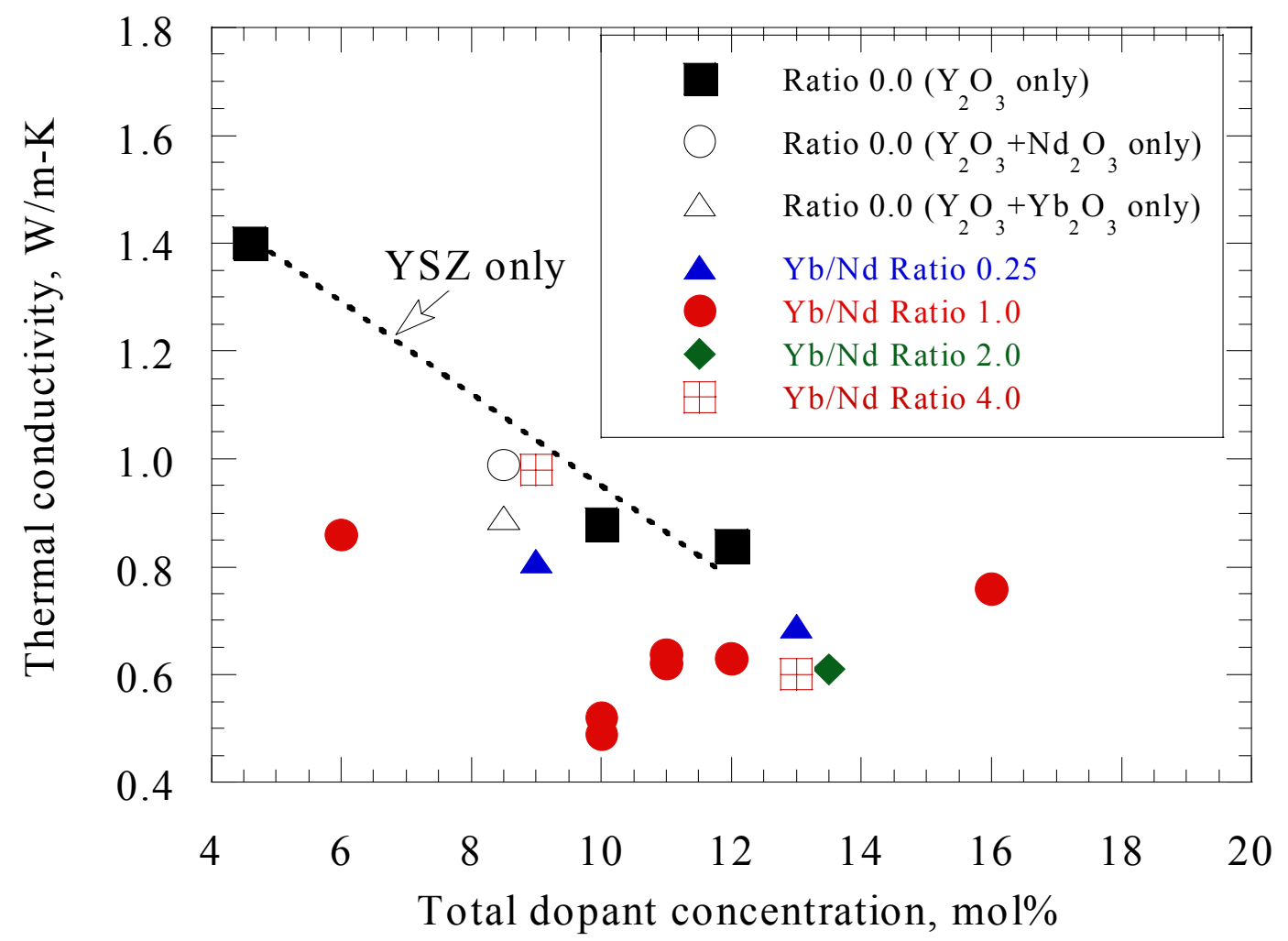

Figure 4. Thermal conductivity of plasma-sprayed $\mathrm{ZrO}_{2}-(\mathrm{Y}, \mathrm{Nd}, \mathrm{Yb})_{2} \mathrm{O}_{3}$ oxide defect cluster coatings as a function of total dopant concentration and cluster dopant concentration ratio of $\mathrm{Yb}_{2} \mathrm{O}_{3}$ to $\mathrm{Nd}_{2} \mathrm{O}_{3}$ (in mol\%) near the optimum low conductivity region. The cluster oxide coatings with the equal cluster oxide dopants $\left(\mathrm{Yb}_{2} \mathrm{O}_{3} / \mathrm{Nd}_{2} \mathrm{O}_{3}=1 \mathrm{in} \mathrm{mol} \%\right)$ showed the lowest conductivity at $10 \mathrm{~mol} \%$ total dopant concentration. 


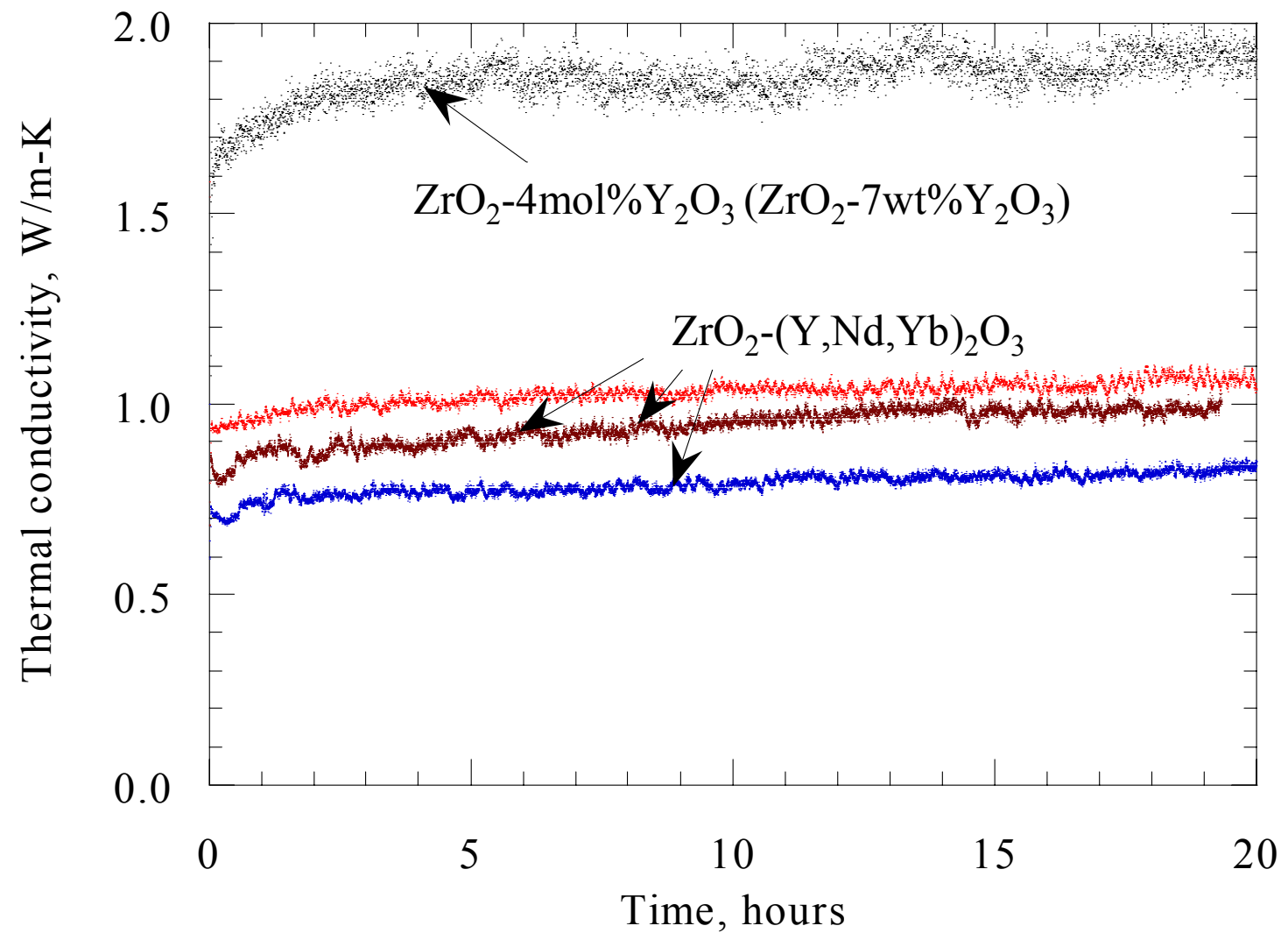

Figure 5. Thermal conductivity of EB-PVD processed $\mathrm{ZrO}_{2}-(4 \sim 6) \mathrm{mol} \%(\mathrm{Y}, \mathrm{Nd}, \mathrm{Yb})_{2} \mathrm{O}_{3}$ oxide defect cluster coatings as a function of time. The cluster coatings exhibit significantly lower thermal conductivity and conductivity-rate-of-increase than the $\mathrm{ZrO}_{2}-4 \% \mathrm{molY}_{2} \mathrm{O}_{3}\left(\mathrm{ZrO}_{2}-7 \mathrm{wt} \% \mathrm{Y}_{2} \mathrm{O}_{3}\right)$ coating. 


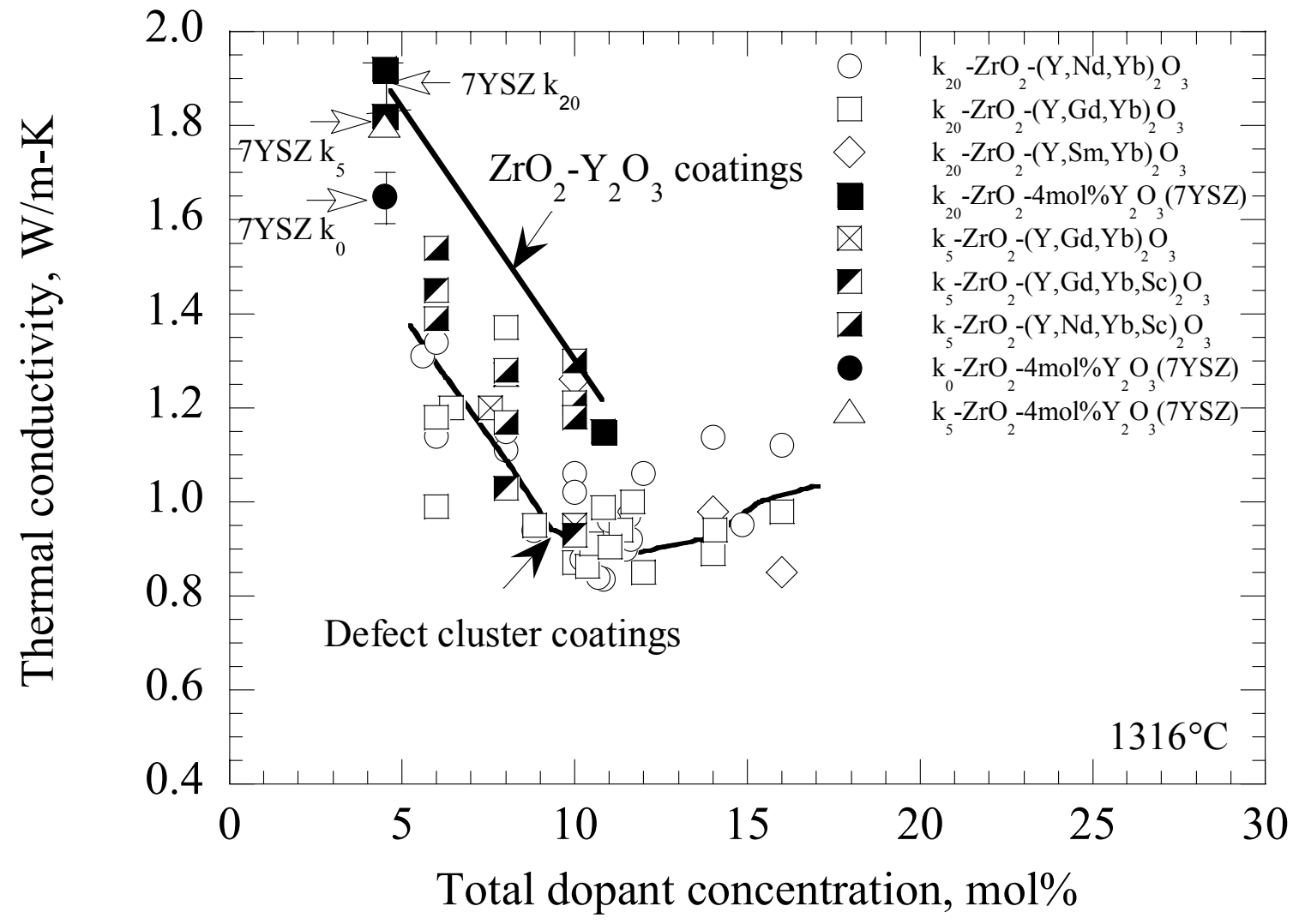

Figure 6. Thermal conductivity of various composition EB-PVD oxide defect cluster coatings as a function of total dopant concentration. Similar to the plasma-sprayed coatings, the EB-PVD coating systems also possess a low conductivity region at about $10 \mathrm{~mol} \%$ total dopant concentration. 


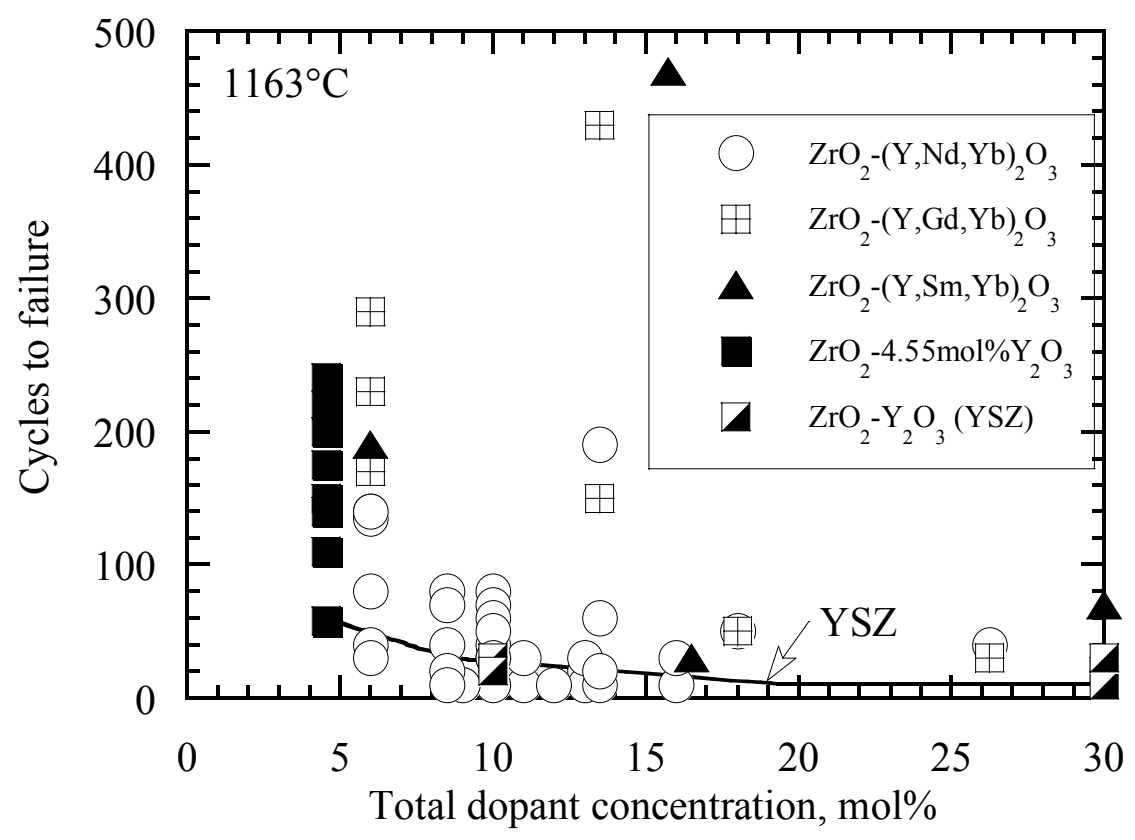

(a)

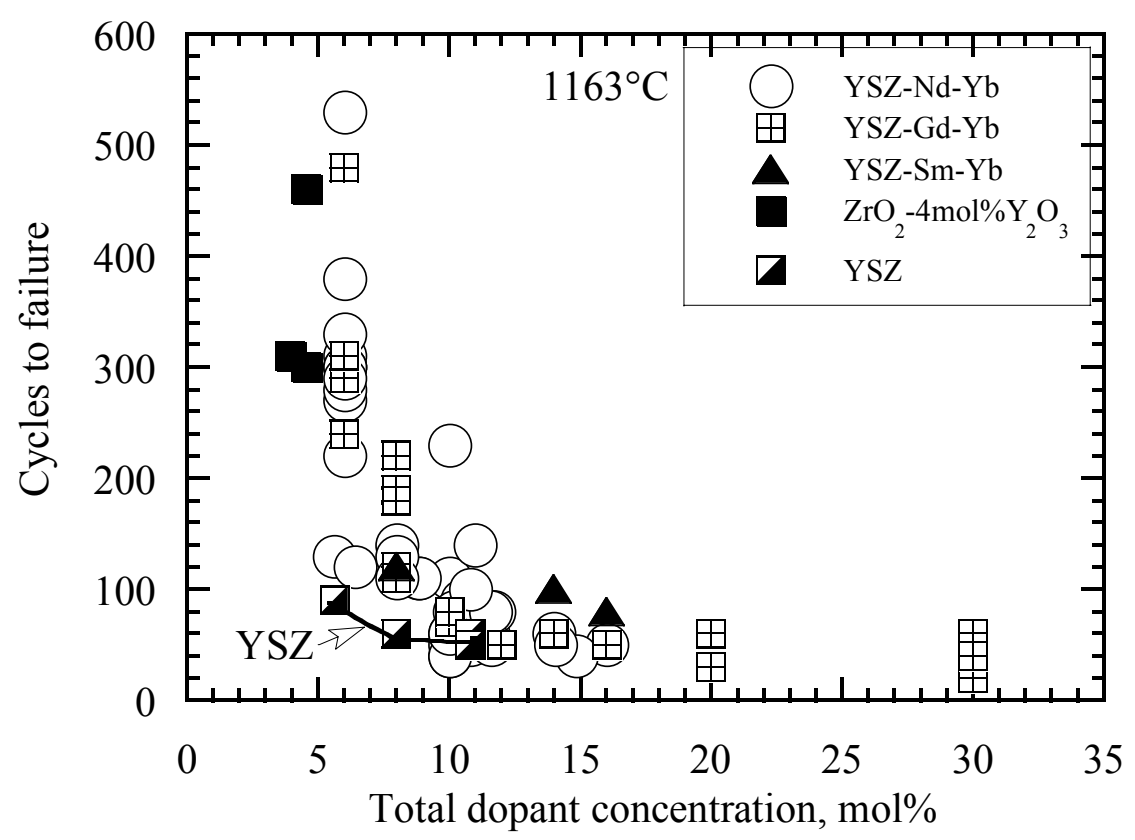

(b)

Figure 7. Furnace cyclic test results for (a) plasma-sprayed and (b) EB-PVD multi-component oxide defect cluster coatings. The coating specimens were cyclic tested in a tubular or a box furnace at $1163{ }^{\circ} \mathrm{C}$ with 45 min hot time cycles (ref. 23). The coating cyclic life generally decreased with increasing the total dopant concentration. The oxide defect cluster coatings showed promise to achieve significantly better cyclic durability than only yttria-doped zirconia coatings at given dopant concentrations. 



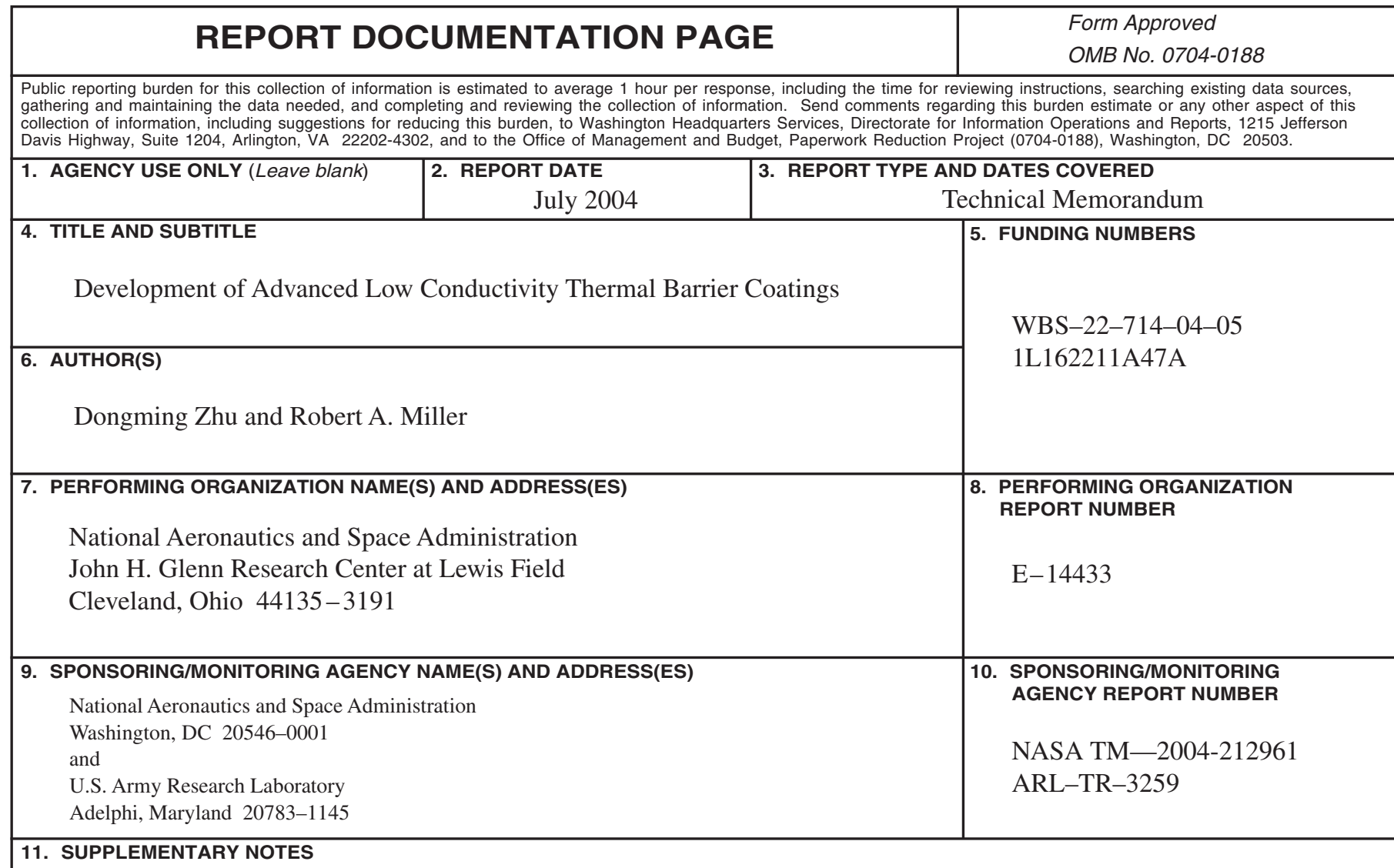

Dongming Zhu, U.S. Army Research Laboratory, NASA Glenn Research Center; and Robert A. Miller, NASA Glenn Research Center. Responsible person, Dongming Zhu, organization code 5160, 216-433-5422.

12a. DISTRIBUTION/AVAILABILITY STATEMENT

12b. DISTRIBUTION CODE

Unclassified - Unlimited

Subject Categories: 23, 26, and 27

Distribution: Nonstandard

Available electronically at http://gltrs.grc.nasa.gov

This publication is available from the NASA Center for AeroSpace Information, 301-621-0390.

13. ABSTRACT (Maximum 200 words)

Advanced multi-component, low conductivity oxide thermal barrier coatings have been developed using an approach that emphasizes real-time monitoring of thermal conductivity under conditions that are engine-like in terms of temperatures and heat fluxes. This is in contrast to the traditional approach where coatings are initially optimized in terms of furnace and burner rig durability with subsequent measurement in the as-processed or furnace-sintered condition. The present work establishes a laser high-heat-flux test as the basis for evaluating advanced plasma-sprayed and electron beam-physical vapor deposited (EB-PVD) thermal barrier coatings under the NASA Ultra-Efficient Engine Technology (UEET) Program. The candidate coating materials for this program are novel thermal barrier coatings that are found to have significantly reduced thermal conductivities and improved thermal stability due to an oxide-defect-cluster design. Critical issues for designing advanced low conductivity coatings with improved coating durability are also discussed.

14. SUBJECT TERMS

15. NUMBER OF PAGES

Thermal barrier coatings; Sintering resistance; Low thermal conductivity; Defect clusters

20

\begin{tabular}{|c|c|c|}
\hline $\begin{array}{c}\text { 17. SECURITY CLASSIFICATION } \\
\text { OF REPORT } \\
\text { Unclassified }\end{array}$ & $\begin{array}{c}\text { 18. SECURITY CLASSIFICATION } \\
\text { OF THIS PAGE } \\
\text { Unclassified }\end{array}$ & $\begin{array}{c}\text { 19. SECURITY CLASSIFICATION } \\
\text { OF ABSTRACT } \\
\text { Unclassified }\end{array}$ \\
\hline
\end{tabular}

NSN 7540-01-280-5500

Standard Form 298 (Rev. 2-89)

Prescribed by ANSI Std. Z39-18 298-102 

